revista ANTHROPOLÓGICAS

Ano 24, 31(1): 169-195, 2020

\title{
El Uso Inapropiado de la Coca o Bien, la Bonanza de la Cocaína desde la Perspectiva Cultural de los Indígenas que Hacen uso del Mambe y Ambil
}

Salima Cure ${ }^{\text {a }}$

Me interesa el tema de la coca, mambe (hojas de coca en polvo), cocaína, hace unos años, cuando realicé mi maestría en estudios amazónicos en la Universidad Nacional de Colombia, sede en la Amazonía. Viviendo y estudiando en Leticia, escuché historias que se referían a la época del tráfico de cocaína de los años 70-80 en el Trapecio Amazónico, relacionado con el cultivo de coca en Bolivia y Perú. También me movía entre historias que abordaban la contemporaneidad de ese tráfico vinculado a Brasil y la ruta de Manaus al Océano Atlántico. Poco a poco, el interés por el tema me llevó a centrarme en las interpretaciones que hacen los indígenas que consumen coca sobre su transformación en cocaína y los efectos que tuvo en sus vidas la comercialización de esa sustancia.

Coca, Cocaína, Murui, Amazonas, Respuestas culturales.

\section{La 'situación etnográfica'}

Pasado mi primer año de doctorado y queriendo adelantar mi investigación sobre memoria y tráfico de cocaína en la triple frontera amazónica durante la década de los años '70 y '80, volví a la ciudad de Leticia, amazonia colombiana, después de 5 años de estar residiendo en Italia. Tenía un particular interés en explorar las prácticas de 'aco-

a Doctora en antropología de la Universidad L'Orientale de Napoli. Integrante del Núcleo de Investigaciones en Etnicidades (NEPE-UFPE). Profesora visitante en el Programa de Posgrado en Antropología (UFPE 2019). Email: salome116@hotmail.com. 
modamiento y resistencia' (Muratorio 1991) frente al dominio cultural y económico que este tipo de capitalismo ilegal promovió en los territorios indígenas donde se instaló. Era el año de 2010, y en la ciudad se percibían fuertes cambios, principalmente en el sector económico, con mayor número de actividades comerciales, tipo boutique, negocios de cosméticos, bebidas alcohólicas importadas, así como más casinos, tanto en lugares céntricos, como en los alrededores del puerto.

A través de los medios de comunicación locales y de mis interlocutores, confirme mis impresiones a propósito de dichos cambios urbanísticos; el tráfico de la cocaína estaba de nuevo sintiéndose en la región controlada por grupos de traficantes colombianos, peruanos y brasileros, con algunos cultivos de coca en cercanías de comunidades Ticuna del lado peruano de la frontera. La ruta de la cocaína seguía por el río Amazonas, hasta Manaos, desde donde era conducida al Océano Atlántico y de allí a diversos destinos del mercado internacional.

En los periódicos aparecían noticias sobre homicidios e historias de personas amenazadas por los traficantes, se publicaban también noticias sobre las propuestas de los tres gobiernos para promover la construcción de bases antidrogas a lo largo de las fronteras. Durante mis recorridos por el río, o los poblados en frontera, me tocó asistir a ejercitaciones militares sobre el río, requisas por las calles, sobre todo de jóvenes, por sospechas de tráfico y venta de cocaína, o de ser mediadores de los traficantes.

Considerando la compleja situación que envolvía mi investigación, y los riesgos concretos de moverme en un territorio disputado por los traficantes y los agentes militares, evite mostrarme interesada sobre el fenómeno de tráfico que se vivía en ese momento, sin embargo, era imposible que no se hicieran conexiones en las conversaciones sostenidas con mis interlocutores, y constantes eran las referencias comparativas entre pasado y presente, a través del uso de comentarios como "mira lo que está sucediendo allá ", "mi pariente está allá", "mira, la gente del Perú tiene buenas casas", "en esos tiempos no era así”, "mejor que no vas a ver porque es peligroso". 
El antropólogo Joao Pacheco de Oliveira, propuso ya hace algunos años un concepto interesante y muy pertinente para este caso, el de "situación etnográfica", a través del cual se pretende "recuperar o etnógrafo enquanto um efetivo ator social, localizando-o dentro de uma rede de relações de força e de sentido, em que o campo do observado e do registrado irá depender de opções realizadas em múltiplas escalas e contextos, operando em reação às expectativas e iniciativas dos indígenas e dos demais atores igualmente presentes no processo de realização de uma etnografía” (2013:230).

Entendida la 'situación' en los términos planteados por Pacheco, era claro que yo no me estaba confrontando solamente con mis interlocutores indígenas, sino con una serie de actores diversos, traficantes, policías, trabajadores de traficantes, que operaban en diversos modos dentro de mi campo de investigación. Por supuesto, eso comporto algunas dificultades, sobre todo en la posibilidad de crear relaciones de confianza que permitieran el desarrollo de esas conversaciones y de ese poder-querer recordar las historias relacionadas con el tráfico de cocaína de los años 70-80. Como nos advierte Grele, "recordar es un trabajo, una práctica, y como tal, es contradictoria, a menudo parcial, sujeta a las contingencias" (2007:XIII - la traducción es mía).

Mis interlocutores, representaban la complejidad de la 'situación etnográfica' en la que la investigación se movía, logré conversar y realizar algunas entrevistas a profundidad con mujeres y hombres Ticuna, Murui, comerciantes, policías, ex traficantes, funcionarios estatales. Nuestros encuentros avenían en diversos escenarios, en sus mismas casas, en los mambeaderos - espacio en las casas dedicado para el consumo de mambe, en parques públicos, en bares. También recorrí la ciudad, observando aquellos 'monumentos-memoria' que evocaban esa primera época de tráfico: casas elegantes, teatros, bares, antiguos prostíbulos, estaciones de gasolina. Igualmente estuve en comunidades indígenas ubicadas sobre el río Amazonas de los tres países en frontera, andando por lugares donde antes operaban pistas clandestinas para el transporte de la cocaína. 
Al cabo de dos meses regresé a Italia para continuar mis estudios, y trascribiendo algunas de las entrevistas realizadas, emergieron unos elementos antes no plenamente considerados que tenían que ver con el modo cómo los indígenas que hacen uso del mambe y del ambil ${ }^{1}$ interpretaron dicho período desde la perspectiva cultural de un uso inapropiado de la coca; me interesé en comprender el sentido de ese 'uso inapropiado'.

Bajo esa nueva pregunta de investigación, viajé nuevamente a Leticia y decidí escribir mi tesis allá ${ }^{2}$ Con ese movimiento, no trataba solamente de subvertir la clásica de Clifford de 'estar allá, escribir aquí', con un 'estar allá, escribir allá', sino que quería estar más cerca de las realidades que constituían ese 'allá. Quería experimentar otro tipo de escritura, no entendiéndola como el acto solitario que seña el final del proceso de investigación de campo, sino como algo en continua construcción, que va de la mano con aquello que Rosaldo (2000) ha definido 'la frecuentación profunda' de los lugares que integran el campo. Quise aproximarla al concepto indígena de 'estar sentada', noción que tiene la connotación de una postura física, el cuerpo presente y atento, escuchando, pensando, haciendo uso de mambe y ambil, y conversando y aprendiendo con los otros. De acuerdo con el antropólogo Luis Guillermo Vasco, es “indispensable sentir, seguir y entender el saber interno de las comunidades, en vez de solo pensarlo, dado que éste nace, se reproduce y se conserva a través de los sentidos" (1999:4-5). La investigación y su escritura fue entendida entonces como ese proceso de "estar sentada”, nutriéndose de esos constantes encuentros y diálogos con mis interlocutores, colegas y otros consumidores del mambe.

\section{De nuevo en campo}

Como afirma Clifford, la noción de campo, ha sido fuertemente debatida en la antropología contemporánea, en cuanto presupone que en ésta estaría operando una "distinción espacial entre una base conocida y un lugar externo de descubrimiento" (1999:72). Un "den- 
tro y fuera" que habrían definido tradicionalmente el campo y el trabajo de campo y que lo distanciarían de la noción de casa, como lugar de lo conocido, cuando, más allá de realidades separadas, "casa” y "campo" son "lugares yuxtapuestos en un proyecto comparativo móvil” (Clifford 1999:102).

En mis viajes de regreso a Bogotá y Leticia, desde Italia, por ejemplo, esas clásicas distinciones temporales y geográficas entre 'casa' y 'campo' no tenían gran sentido, no era posible distinguirlas como espacios diversos, pues ambos lugares estaban atravesados por sensaciones de distancia, experiencia, afectos, y conflictos.

Además, de acuerdo con Deborah D’Amico-Samuels, en el mundo globalizado y altamente tecnológico de hoy "casa y campo existen en el mismo contexto holístico de globalizadas relaciones de poder" (citada en Sluka \& Robbens 2007:25 - la traducción es mía). Dicha afirmación resulto especialmente evidente en aquellos lugares intermedios, o bien, para decirla con Fabietti, aquellos lugares transitados "para ir allá" (citado en Urbinati 2008:28), como los aeropuertos, donde el control y relaciones de poder vienen ejercitados por policías y agentes de aduana y migración que justifican sus prácticas también en nombre de la 'lucha contra las drogas'. Recuerdo, por ejemplo, un policía en el aeropuerto de Bogotá que miraba sospechosamente mis libros que tenían en sus títulos las palabras coca y cocaína, le explique que era mi investigación, a lo que me respondió con una escueta frase, "ah, eso se estudia”.

El argumento de mi investigación, o mejor, la coca, ya estaba presente en tales lugares, por lo que los espacios transitados para ir al campo, eran ya parte de la 'situación etnográfica', en cuanto escenario de relaciones que se van construyendo en el desarrollo de la investigación.

Vale la pena evidenciar que ese campo fue construido así mismo desde la multilocalidad, una 'etnografía multilocal', como diría Marcus (1997). El 'campo' no fue un lugar concreto en el cual practicar una residencia intensiva, sino una red de interacciones con diversas 
personas en variados lugares; fue el argumento de la investigación a situar el campo, en dicho sentido, de acuerdo con Carolyn Nordstrom "el proceso y la gente suplantaron el lugar como 'lugar etnográfico"” (2007:252 - la traducción es mía).

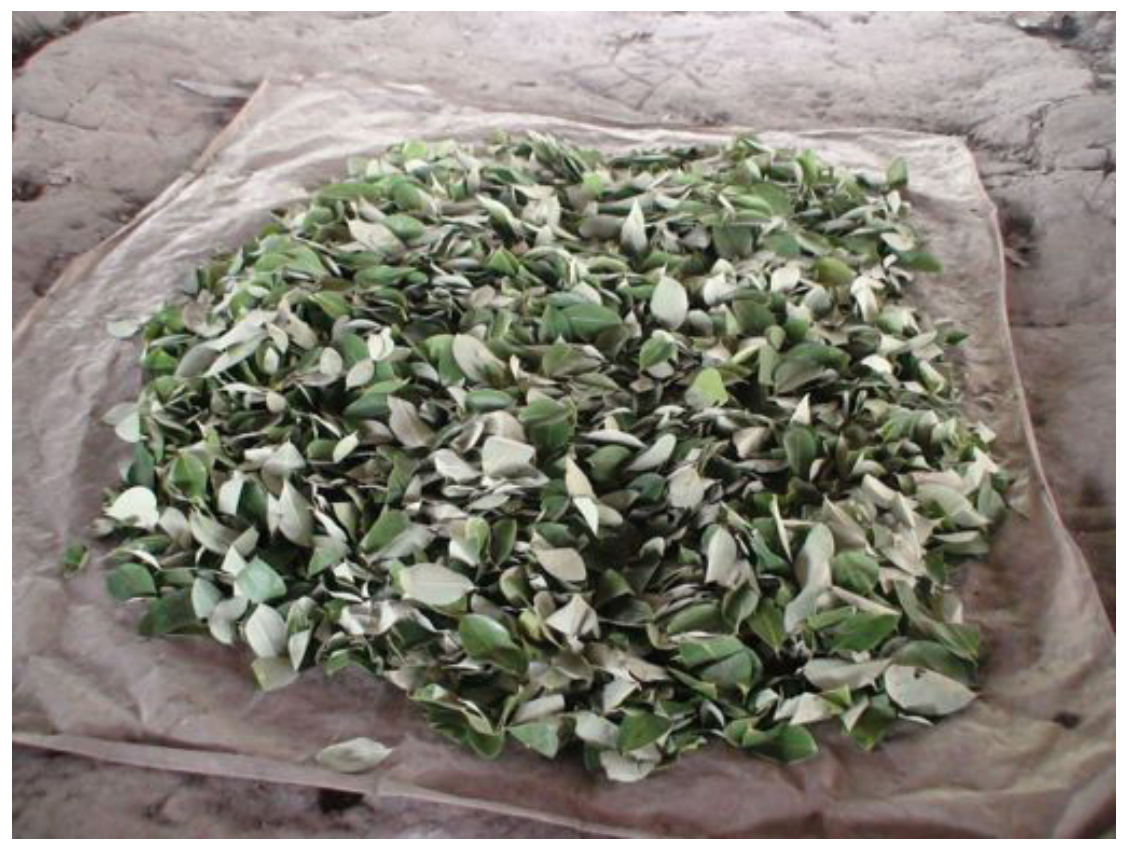

Fig. 1. Hojas de coca colectadas para ser quemadas y mezcladas con ceniza y preparar mambe. Foto del autor.

En un interesante artículo sobre la economía de la práctica etnográfica, el antropólogo Cristiano Tallé reflexiona sobre como "el saber etnográfico, lejos de ser el fruto de una observación desinteresada, es resultado de una ganancia simbólica producida en el trabajo de investigación, mantenido en vida a través de una cadena de reconversiones reciprocas de intereses siempre presentes, jugados aquí y allá, y difícilmente irreductibles a un mero negocio económico” (2007:166). 
La observación de Tallé me resultó bastante perceptible cuando en mi trabajo, la posición de antropóloga fue acompañada por otra posición. Hablando de coca y mambeando con indígenas Murui, Bora, Muinane, Ocaina, Miraña, que además vendían mambe, me volví una cliente. Inicialmente, no entendía la importancia de dicha colocación, he sido consumidora de mambe por algunos años y solía comprar a unos y otros, pero en el marco de la investigación, comprar se volvió un compromiso, un modo reciproco de intercambiar el tiempo concedido para conversar, con la compra de sus productos, que era al mismo tiempo, el tema central de mi investigación.

Teniendo mambe, era obligada a compartirlo en los mambeaderos con las personas que ahí encontraba y con quien dialogaba. En esos contextos de diálogo y compartir el mambe, fue útil la definición de 'participación’ propuesta por Alesandro Duranti (2005), para evidenciar la importancia de este acto en el proceso de producción de la experiencia etnográfica. Duranti hace referencia al hablar como una actividad social, en la cual los eventos comunicativos y las relaciones concretas que se construyen implican la participación de un colectivo de hablantes y oyentes, de actores sociales que interpretan, aprueban, evalúan, desaprueban y dan significado a aquello que se está enunciando.

La participación, si bien implica compartir recursos tanto materiales como simbólicos, como el mismo uso de la lengua, no significa que el conocimiento o el control sobre tales recursos sea igualmente compartido. El de la participación, argumenta Duranti, "es un concepto analítico que toma el lugar de viejas dicotomías como aquellas de hablante-oyente o emitente-receptor" para subrayar en cambio que "el significado es frecuentemente creado por la yuxtaposición de diferentes voces" (2005:30). Esto se demostró particularmente evidente en los mambeaderos urbanos de Leticia, donde el diálogo se construye entre todos los presentes en un acto interactivo-performativo, que es guiado por un interlocutor principal.

En el mambeadero, el discurso es profundizado, no hay necesidad de síntesis, se libera en un coro de relatos antiguos y actuales, que re- 
corren la memoria de los más ancianos y que van demarcando el contorno de las otras palabras que se dicen en dichas conversaciones. Las preguntas hechas, o las que yo hacía, no tenían respuestas inmediatas, sino que llegaban a través de vuelos pindáricos, el abuelo del mambeadero recoge todo, mostrando una fina capacidad argumentativa y de síntesis, así como habilidad en mantener un hilo conductor en el discurso. Y todo eso, 'sentados', y esto es sin duda es el aspecto más difícil, sobre todo, para quien, como yo, está habituada a pensar con la cabeza sin considerar el cuerpo. 'Estar sentados' en bancos bajos hechos en madera, sin alzarse, bajando la cabeza en el momento de la escucha de los otros, en un acto corpóreo que nos demuestra como el cerebro es un todo con la columna vertebral.

\section{El sentido de la palabra bonanza}

.... por lo menos

hasta ahora que yo sepa

la bonanza del caucho eso fue a mis abuelos

la bonanza pielera

la bonanza maderera

en esa sí no me metí

la bonanza coquera

ese auge en que uno trabajo

ahora la bonanza de corrupción institucional..... (Armiro).

Las palabras de Armiro, indígena Ocaina quien vive en una comunidad cerca de Leticia, son bastante significativas en cuanto nos proponen un marco de referencia para comprender lo que localmente se entiende por bonanza y ese continuo de ciclos económicos que han pasado por la región amazónica. Es una palabra que me gusta usar porque es una categoría localmente muy presente y porque denota bien ese tipo de 'abundancia ilusoria' de la que habla el historiador Hermes Tovar (1994).

Podemos decir que la bonanza es un período en el cual se tiene la ilusión de que está por llegar un momento de crecimiento económico, pero eso no ocurre, por el contrario, la ilusión explota y las condicio- 
nes socioeconómicas no mejoran, o no para la gran mayoría de los habitantes, pueden incluso empeorar. Una bonanza es la antesala de otra bonanza, son presencias efímeras.

Si bien el tiempo del capitalismo suele darse en un modo lineal, en modo progresivo, el modo como éste se ha presentado en la región amazónica parece ser más circular, proponiéndose periódicamente en la historia de la región y en la vida de las personas. Circularidad que recuerda el subir y bajar de los ríos, aguas altas, aguas bajas, estaciones que marcan profundamente el ritmo de la vida en esta inmensa región.

Tener presente el continuo de bonanzas en la Amazonia permite entender mejor la de la cocaína, en cuanto no aparece como un evento nuevo, aislado, sino que es un modelo reconocido de participación en el ideal capitalista de progreso económico, que de acuerdo con el antropólogo Fernando Santos Granero, "se inscribe al interno de una larga lista de ciclos productivos y extractivistas que caracterizan la historia económica de la Amazonia en la conexión con la globalización y las demandas del mercado internacional" (1991:256). La bonanza de la cocaína puso en contacto el Amazonas con diversas regiones del mundo, incluso con la misma Colombia, lo que no significó bienestar o mejor calidad de vida para los habitantes locales, por el contrario, el carácter ilícito determinado para dicho mercado implicó inestabilidad social, política y económica, así como difíciles condiciones para los grupos sociales ahí presentes.

Las bonanzas del caucho, de la madera, de los animales y sus pieles, que nombraba Armiro, crearon una estructura comercial útil a aquella de la cocaína, una estructura en parte manejada por agentes locales que contaban con una estructura comercial establecida, muchos de ellos posicionados en roles de patrones, y que se articularon a grupos externos que controlaban las rutas del tráfico de la sustancia.

A partir de conversaciones sostenidas con diversas personas por diversos años, entendemos que esas bonanzas han sido experiencias interpretadas y manipuladas por los mismos sujetos. Mi experiencia 
investigativa me ha llevado a entender que dichos sujetos han sido actores activos, y no pasivos, en la creación contemporánea de su propia historia, y han incorporada cada bonanza en su historia de vida. De acuerdo con Hugh-Jones (1988) en las aproximaciones antropológicas clásicas se ha privilegiado la imagen de la pasividad de los indígenas frente al avance de la economía de mercado en sus territorios, cuando también ellos, no obstante, la explotación intrínseca a ésta, han sido participantes activos y creativos en un proceso bilateral. Según Roseberry, sería más fecundo pensar la articulación del capitalismo en distintos lugares del planeta no sólo en términos de una estructura dominante, sino también desde la agencia de los sujetos, en aquello que la gente real hace realmente - "real people, making real thing" (Roseberry 1988:172). Esto no quiere decir negar el carácter problemático de la inequidad que genera el capitalismo, pretende en cambio, parafraseando a Muratorio (1996), situar históricamente las voces subordinadas en los contextos más amplios de la economía política mundial con el ánimo de comprender la complejidad que los efectos del capitalismo genera en estas poblaciones y su respuesta a tales efectos.

La bonanza adquiere entonces el sentido de la experiencia, entendida ésta, usando las palabras de Paolo Jedlowski, como "sedimentación y elaboración de vivencias en vista de restablecer una continuidad que es entendida como capacidad de dar significado al presente" (2002:38 - la traducción es mía). Bonanza entendida como experiencia vivida que da un sentido a situaciones que se representan en el presente, produciendo memoria individual y colectiva, así como lo relataba Armiro nombrando lo vivido por él y su familia.

Ahora bien, la bonanza de la cocaína comportó algunos elementos nuevos; en primer lugar, tenía la connotación de ilegal, el nuevo producto debía esconderse, era secreto y no todos podían saber. Claro, esa línea entre lo legal y lo ilegal era poco clara, de acuerdo con la geógrafa Lia Machado (2000), las condiciones de legalidad/ilegalidad es mutable en el tiempo y en el espacio, porque lo es el aparato normativo, discursivo y técnico que lo soporta. Las llamadas drogas 
están interrelacionadas con una particular matriz institucional y son controladas por la ley, sea a través de prescripciones médicas o de una legislación que prohíbe el comercio de aquellas usadas por fuera del contexto médico, volviéndose ilegal y sancionable su posesión. Como sostiene Sherratt (1998) en la introducción del libro Usi sacri, consumi profani, las categorías de licito e ilícito no son estáticas, ni rígidas, son 'categorías del discurso', o bien, que el límite entre lo uno y lo otro es mutable y negociable desde el punto de vista histórico y cultural y no debe por lo tanto ser asumido como algo inequívoco.

En aquella época, en el Trapecio Amazónico, las autoridades locales eran en buena medida permisivas con el tráfico, además buena parte de la economía de la región dependía y se organizaba entorno al tráfico, lo que de cierta manera lo legitimaba entre pobladores locales, trabajadores indígenas y no indígenas, autoridades. De hecho, conversando con diversas personas que en la época trabajaron en laboratorios y pistas, la percepción que aparece es la de que se trataba de un trabajo, un modo de acceder al dinero. Esto no quiere decir, que la percepción del peligro estuviera ausente. Las personas sentían que era un trabajo que comportaba ciertos riesgos.

El otro elemento nuevo que la bonanza de la cocaína comportó fue el dinero, o bien, la cantidad de dinero que circuló y que, si bien quedó especialmente en la mano de los patrones y comerciantes, como en las anteriores bonanzas, también llegó a más personas. De hecho, el dinero fue el instrumento utilizado por los patrones para crear alianzas con diversos sectores de la sociedad y así blindarse ante las acciones que la policía o militares pudieran hacer contra ellos.

\section{Traficantes locales y sus redes externas}

Al inicio de los años '70, comenzaron a consolidarse los grupos de traficantes de cocaína en algunas regiones del país, entre ellos los más influyentes los de Medellín, Cali y el núcleo Central. Ellos controlaban la producción de la cocaína y poseían las rutas y los contactos para su comercialización en los Estados Unidos, dos elementos claves para 
mantener su hegemonía en el continente latinoamericano durante los años 70-80. El único pasaje sobre el cual no tenían control total era el de los cultivos de coca, que era menor respecto a los números actuales, esto, los rendía dependientes de las importancias de la pasta base producida en Bolivia y en la Amazonia peruana. Leticia, la ciudad más austral de Colombia, representó para los traficantes la oportunidad para tener un lugar cercano a las zonas productoras, y, por lo tanto, su control en la compra y venta.

La zona del Valle del Huallaga, en los departamentos de Huanaco y San Martín en el Perú, fue en las décadas de los '70-'80, una de las mayores zonas productoras de hoja de coca para producción de cocaína del Perú y del mundo (Soberón 2009); una zona donde se vivía un estado de violencia latente actuado por los traficantes organizados en 'firmas'- denominación usada en Perú para hablar de los grupos de traficantes- la policía, el ejército y la guerrilla maoísta de Sendero Luminoso que entró en el mercado de la coca en los años '80 en el tentativo de garantizar precios justos para los campesinos y de controlar la zona. Según el politólogo Pablo Dreyfus (1998) las 'firmas' peruanas en ese entonces eran estructuras muy débiles y estaban integradas y subordinadas al proceso de producción de cocaína de las organizaciones colombianas, ellos se encargaban de los primeros procesos de transformación de las hojas de coca en pasta base. ${ }^{3}$

La ruta por el río Amazonas jugó un rol fundamental para el transporte y comercio de la pasta base de coca. Barcos veloces con potentes motores la transportaban desde Pucallpa, en la Amazonia peruana, pasando por Iquitos, Leticia y posteriormente a otras zonas de Colombia. Fueron posteriormente las avionetas, y las pistas clandestinas construidas tanto en la zona del Valle del Huallaga, como en las cercanías de Leticia, o mejor, en los alrededores de las comunidades indígenas, las que le dieron a dicha bonanza mayor potencialidad.

Si por el río lograban transportar 10, 20, 50 o 80 kilos de pasta base, con las avionetas llevaban cantidades superiores, 300 o 400 kilos por viaje. Estas grandes cantidades hicieron consolidar la pequeña 
ciudad de Leticia en un importante centro de negocios, de diversos tipos de negocios, tanto de las sustancias químicas necesarias para la transformación de la pasta base, como la del dólar, el cual circulaba en contante en las mismas avionetas.

\section{Lugares de la bonanza: pistas y laboratorios clandestinos}

Los patrones y las personas que trabajaron en tal tráfico hicieron de la opulencia un estilo de vida, un escenario de consumo demostrativo que se evidenciaba en las fiestas, los bares, discotecas, hoteles, galleras, donde se gastaba el dinero conseguido en la bonanza. Dichos traficantes se volvieron 'role models', usando las palabras de Castells (2008), para los jóvenes indígenas y no indígenas del Amazonas, instaurándose en ese modo un cierto deseo de ser como los patrones, imitando sus estilos de vida y queriendo adquirir el dinero en modo rápido.

Los dineros de la bonanza favorecieron diversos sectores económicos de Leticia, y de la ciudad fronteriza de Tabatinga. Uno de los más beneficiados fue el mercado relacionado con las importaciones de materiales de construcción, electrodomésticos, carros y motos, así como alimentos, bebidas alcohólicas y tabacos. Un movimiento de dinero que fue al tiempo transformando la pequeña ciudad amazónica, pasando de una arquitectura caracterizada mayoritariamente por casas de madera, a construcciones de cemento, algunas bastante lujosas como la de Evaristo Porras y la de otros patrones regionales. La ciudad empezó a moverse en motos y en el río circulaban barcos con motores más potentes, sobre todo en las noches.

Dicha bonanza comportó igualmente la llegada de importantes flujos migratorios, llegaba gente de comunidades indígenas, ciudades pequeñas, pero también de ciudades más grandes, todos queriendo aprovechar la abundancia de dinero y oportunidades de trabajo como comerciantes, joyeros y mujeres que ejercían la prostitución.

Las comunidades indígenas, quienes constituyeron la principal mano de obra en las pistas y en los laboratorios, vivieron considera- 
bles transformaciones. De acuerdo con la antropóloga Blanca Muratorio (1996), el proyecto cultural que conlleva consigo el capitalismo, importó entre los indígenas, nuevos significados y prácticas sobre el tiempo, el espacio, la identidad y el trabajo.

La construcción de las pistas y los laboratorios en cercanía de las comunidades, implicó una nueva espacialidad social, en el sentido que propició nuevos procesos de ocupación del territorio útiles al tráfico de cocaína. Nuevas casas y con nuevos estilos fueron construidas, nacieron pequeñas actividades comerciales y en algunos casos, como fue el caso de la comunidad de San Juan del Soco, ubicada sobre el río Loretoyacu, a 4 horas de Leticia, sus casas fueron reubicadas para dar espacio a construcción de la pista clandestina. El espacio se modificó para responder a las necesidades del tráfico, convirtiéndose, las pistas, los laboratorios y los caminos que los unían en los ejes principales de las comunidades. Así me relató don Alfonso, indígena Ticuna, habitante de la comunidad en esa época,

En aquel tiempo yo tenía 9 años y fue ahí que iniciaron a venir ciertas personas de afuera, en aquel tiempo éramos inocentes, no sabíamos que era eso y ellos llegaron y hablaron con las personas y dijeron que harían una pista, laboratorios, pistas para las avionetas. En aquel tiempo la gente no sabía que cosa era, solo que les pagarían y ya con esta mentalidad del dinero la gente se decidió a trabajar con ellos, e hicieron la pista e hicieron construir la pista, e hicieron construir a la gente el laboratorio y así fue que inicio la bonanza y la historia de la coca y ellos empezaron a venir aquí y la gente sin saber qué era eso, todos inocentes. Solamente ellos sabían lo que estaban haciendo y la gente empezó a trabajar así... antes las casas eran sobre la ribera del río, cuando vino la bonanza propusieron a la gente de mover las casas hacia atrás y las movieron y delante quedó la pista y todo esto se hizo porque había dinero en aquel período...y cortaron los árboles para mover las casas, y eso fue lo pasó y ahí inició el trabajo....

El trabajo dedicado para el tráfico de cocaína implicó así mismo una transformación a nivel temporal. En las sociedades amazónicas el tiempo para ir a la chagra, la cacería, la pesca, suele responder a 'de- 
cisiones situacionales' (Brody en Rosaldo 2000), lo que quiere decir, que se decide en el momento dependiendo de si llueve, o hace sol, si llegan visitas, si se quiere, si se necesita. En la bonanza, por el contrario, se impusieron ritmos de trabajo que debían ser cumplidos en un modo puntual y horarios específicos dependiendo de la llegada de las avionetas para transportar las mercancías, descargar, y procesar la pasta base en los laboratorios.

Los trabajadores recibían dinero por su trabajo, esa fue una diferencia con las anteriores bonanzas en las que operó el sistema de endeude, ese vínculo comercial ficticio, como lo define Taussig (2005), en el cual el endeudado no era un esclavo, ni un asalariado, sino un sujeto obligado a pagar su deuda. Aunque hubo casos, sobre todo al final de la bonanza, en que la gente recibía como pago la misma pasta base, la cual era vendida o consumida directamente.

\section{Interpretando la crisis}

La coca no golpeó a los paisanos Ticuna, ni a los Yagua, ni Cocama. Cierto, ellos trabajaron, pero no eran de ese canasto. (Alberto).

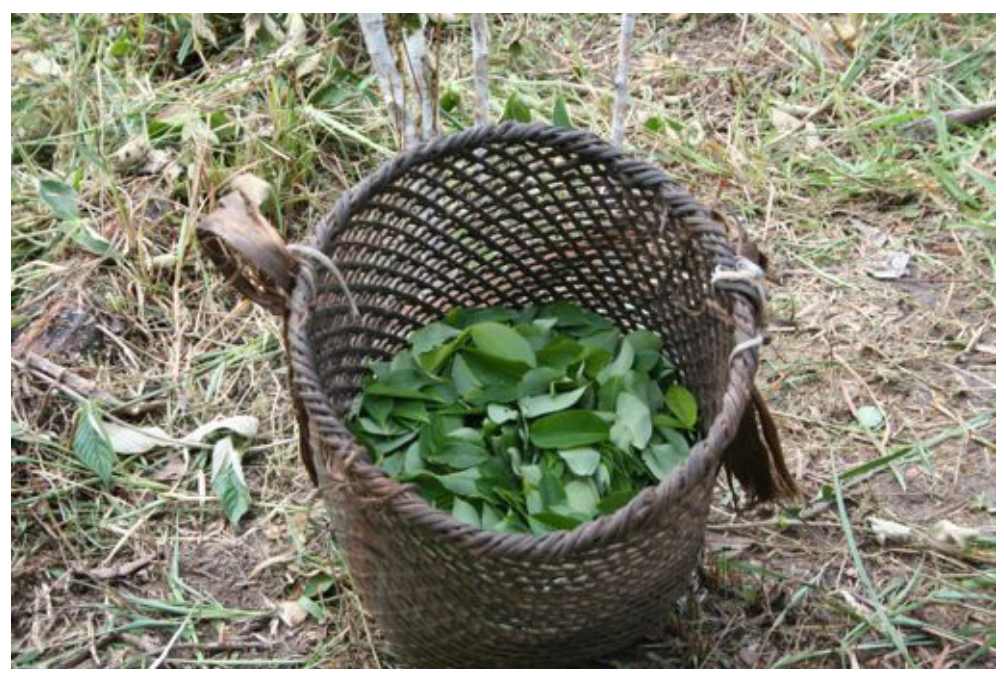

Fig. 2 Hojas de coca en un canasto. Foto del autor. 
En una entrevista realizada con Alberto, indígena Murui, él me decía que si bien indígenas, Ticuna, Yagua y Cocama trabajaron en los tiempos de la bonanza, esto no los golpeó como a ellos, en cuanto ellos "son gente de otro canasto". La figura del canasto dentro del pensamiento Murui es una imagen metafórica de diversos procesos. Como nos señala Edmundo Pereira, tal imagen es usada por los Murui "para hablar de la vida, de los procesos vitales, de la adquisición de conocimiento, de la constitución de gobierno, de la organización de un pueblo" (2005:5 - la traducción es mía). Esa se refiere también a la construcción de una identidad y de un origen común.

Alberto a través de la imagen del canasto quería decir que los Ticuna, los Cocama y los Yagua, son personas con orígenes diferentes, tienen otro modo de pensar, no son gente de coca, o bien, ni cultivan, ni consumen coca, ni manejan la coca, no son, por tanto, parte del mismo canasto del cual han sido formados los Murui. En ese sentido, para Alberto, si durante la bonanza ellos trabajaron con pasta base de coca o fumaron basuco ${ }^{4}$, no se les pondría el problema moral que si se pondrían indígenas que consumen mambe y ambil por haber hecho un uso 'inapropiado de la coca'.

Expresiones como 'la coca fue profanada' o se 'jugó con la coca' fueron ampliamente usadas para dar significado a lo que sucedió. Alfredo, otro indígena Murui, describió la experiencia de la bonanza como un evento que al final les dejó mucha hambre y esto es una referencia interesante porque nos conduce a la experiencia de la bonanza como una abundancia ilusoria, una suerte de abundancia de mercancías, dinero, lujos, que en un breve periodo pasa y se vuelve un lejano recuerdo materializado en hambre.

Te contaré como vivimos el tiempo de la bonanza de la coca. Esto sucedió aproximativamente en el ' 86 , antes de que la comunidad supiera de que cosa se trataba, teníamos cultivos, y ahí nos informamos que era la famosa cocaína, llegaron los peruanos y nos enseñaron el proceso de la hoja, y al ver que compraban por gramos y que al tiempo tenía un alto costo, entonces cuando nos dimos cuenta nos dedicamos solo a plantar coca. Todos trabajábamos, se 
olvidaron de sembrar yuca, plátano, de todas nuestras costumbres, eran pocos los que mambeaban la coca, pero todos la transformábamos en cocaína....

La mayor parte de las personas tenía esos cultivos y cuando empezaron la erradicación fue como te digo, un cambio, y al final llegó la crisis, donde uno quedo dependiente... quedó el hambre, ya nadie sembraba nada, la comida llegaba de la ciudad, iy cuando la erradicaron que se comía? Tocó aguantar hambre, mucha hambre, tantísima hambre....

Esa efímera bonanza, de la que nos habló Alfredo, es antagónica a la noción nativa de 'abundancia' que manejan los Uitotos, esa que es valorizada culturalmente, y que es contenida en esa que Echeverri (1997) ha denominado 'la filosofía del hacha'. Esta filosofía es un producto de aquello que implicó la llegada de ese objeto de metal en dichas sociedades; por un lado, conflictos y muertos para acceder a su posesión, por el otro, mayor producción agrícola, lo que fue el soporte para construir una ideología del crecimiento, de la multiplicación del trabajo agrícola, de los alimentos, de la reproducción de la familia. La metáfora fundamental de esta filosofía, sostiene Echeverri, es "el crecimiento del tabaco, la coca, todos los tubérculos, y los arboles de frutos cultivados" (1997:97 - la traducción es mía), con el fin de mantener una buena socialidad, buenas relaciones, solidaridad y hospitalidad.

Durante la bonanza de la cocaína, el trabajo concebido como 'verdadero', o bien, el trabajo, valorizado culturalmente, relacionado con la filosofía de hacer abundar, prácticamente desapareció, al fin de dedicarse exclusivamente a los trabajos pedidos por los patrones. Con el abandono de la chagra, no colocaron solo en riesgo su autonomía alimentar, dejándolos dependientes del dinero para comprar alimentos, sino el abandono de aquello que la antropóloga Valentina Nieto define "el modelo de las concepciones locales sobre el trabajo...." (2006:176). Las concepciones de trabajo en estas sociedades amazónicas, coincidiendo con la tesis de Blanca Muratorio (1991) no posee el mismo significado general que tiene en la cultura llamada occidental, su interpretación es relacionada con la laboriosidad que implica vivir 
en y de la selva. La concepción del trabajo está investida de un alto significado moral, 'work ethic' (Muratorio 1991), en cuanto tiene que ver con la construcción de mujeres y hombres como sujetos morales. De acuerdo don Griffihs (citado en Micarelli 2012), desde la perspectiva Murui, "el trabajo es la fuente que recrea continuamente el cuerpo humano, la identidad, la sociedad, así como la vida y el cosmos. El trabajo construye la identidad tanto colectiva cuanto individual, tanto como relaciones que definen la identidad, el género, la edad, tanto como un talento especial que define la creatividad de un individuo" (2012:23-24 - la traducción es mía).

Y para ilustrar lo que sucedió en los tiempos de la bonanza, Alfredo, Alberto y otros interlocutores utilizaron expresiones como la gente "se olvidó de trabajar", "la gente ya no trabajaba", haciendo principal referencia al abandono del trabajo de la chagra.

En aquel tiempo, dijo doña Blanca, una mujer Murui, la "gente quería ser igual a los blancos”, una expresión que revela muy bien lo que veníamos diciendo sobre las concepciones locales del trabajo, o sea, el trabajo le da una continua forma a la identidad personal y colectiva. Durante la bonanza no se reconocía en el propio trabajo, sino en la imitación de aquello que hacían los patrones blancos y eso se evidencio sobre todo en el ámbito de consumo de ciertos bienes. La gente, decía igualmente Blanca "quería comer como los patrones, quería beber lo que ellos bebían, ron, whisky, cerveza, no se preparaban más la bebida tradicional". Recuerda que tampoco querían pescar, "el pescado en aquella época era considerado de pobres y comían sobre todo la carne que consumían los blancos, pollo, carne de res, enlatados". La percepción de esa pobreza tenía que ver con que el estilo de vida no se acercaba aquel promovido pos los padrones.

La comida comprada, se convirtió, como los vestidos, electrodomésticos, en una mercancía de la distinción, del prestigio, de la ostentación, asumiendo funciones simbólicas como demostrar que se era apreciado por los patrones. En este sentido, tuvo mucho efecto la construcción de una imagen del 'buen patrón' entendido como 
un 'distribuidor de la riqueza' (Geffray en Bonilla 2007). Es preciso resaltar que compartir es un valor muy apreciado socialmente en estas sociedades amazónicas, mientras que ser mezquinos, es condenado socialmente, y es casi siempre asociado al modo de ser de los blancos. El buen patrón es aquel que da trabajo y paga bien, regala dinero para eventos particulares, es generoso, se familiariza con la gente de la comunidad. La dependencia al patrón era creada a través del dono, un dono generoso que, como sostienen Bourdieu, crea y mantiene obligaciones morales y relaciones afectivas. "Se posee para dar. Pero se posee también al dar" (1991:212). Añadiendo que "el don que no re restituye puede volverse una deuda, una deuda durable..." (1991:212), una obligación moral con el patrón que se traducía en no denunciarlo, ni 'fregarlo', o bien, no robarlo, no engañarlo.

Es significativo así mismo subrayar que el dinero ganado en la bonanza, era percibido como 'maldito' en cuanto provenía de una actividad que, si bien no era concebida por ellos como ilegal, si era percibida como peligrosa, cargada de una atmosfera de riesgo. A ese dinero se le confería la capacidad de 'gastarse solo' o sea, un dinero que no 'se dejaba ahorrar', sino que era consumido lo más rápido posible y en modo excesivo en rumbas, alcohol y prostitutas.

\section{Respuestas culturales a la crisis}

Cuando la bonanza de la cocaína pasó, entorno a la mitad de los años 80 ', llegó un período interpretado por los interlocutores indígenas, como lo dijo el mismo Alfredo, como 'crisis', o bien, siguiendo a Micarelli, "la pérdida del control que se vuelve patógena, repercutiendo sobre la salud a nivel físico, psicológico, ambiental y cosmológico" (2012:7 - la traducción es mía). Como ha sido demostrado desde la perspectiva crítica de la antropología médica, "la enfermedad es definida, construida y vivida en un continuo proceso dinámico de acuerdo con diversos momentos históricos y diversos contextos culturales" (Pizza 2005:82 - la traducción es mía). En el pensamiento Murui, la enfermedad es entendida como un estado que puede darse a través las 
relaciones con la gente blanca, "la naturaleza contaminante del mundo de los blancos es asumida por la axiología tradicional Uitoto en una categoría de enfermedad..." (Micarelli 2003:37 - la traducción es mía).

En las narraciones de diversos indígenas Murui, tal 'crisis' fue presentada de hecho como algo producido por los blancos. Para interpretar el origen de la 'crisis' ellos le dieron una lectura cultural, haciendo una distinción ontológica entre la coca - jibina - como "nuestra coca" y la cocaína -y basuco- que material y simbólicamente está relacionada al mundo de los blancos. La cocaína, decía Alfredo, "no es nuestra, es un poder de los blancos para ganar dinero", "es la coca de los blancos y su espíritu es de fuego", sostenía así mismo don José (en Urbina 1992), estimado sabedor Murui, muerto algunos años atrás. Usando una categoría Murui se diría que la cocaína es una sustancia 'caliente', o bien, una sustancia asociada a experiencias sociales conflictuales, como la enfermedad, la ira, la muerte. La madre de Alfredo, doña Rosa, afirmó "en aquel tiempo, enloquecimos, tocamos eso, ya no cultivamos yuca, éramos locos, esa cosa nos dañó...”.

Al mismo tiempo, vale la pena resaltar que tanto Alfredo, Alberto y otras personas, consideraban que ellos mismos eran responsables de la creación de dicha enfermedad. En las concepciones de la enfermedad y la salud entre los Murui, es central la idea de que la "enfermedad es causada por mal uso de los saberes..." (Micarelli 2003:143 - la traducción es mía).

...aquí hicimos un mal uso de la coca, un uso inadecuado, porque ese no es nuestro mundo, nuestro mundo es tener la planta de coca para aconsejar, para enseñar a las personas, para nuestras reuniones, para la cacería, para curar a una persona que está mal. Fue ahí que la usamos mal, y seguramente por este motivo la comunidad, digo yo, la comunidad soportó mucha hambre, no teníamos nada que comer, a quién andábamos a pedir, es el nuestro destino... (Alfredo).

Un uso inadecuado de la coca que se tradujo, desde su perspectiva, en enfermedad, o bien, alcoholismo, dependencia al basuco, descuido de los niños, destrucción de las familias y tanta hambre. 
Wenceslao, otro indígena Murui dijo, "no sólo el tráfico es problemático, también lo es el uso inapropiado de la coca". Este tipo de interpretaciones podría ser vista como un modo de huir al victimismo, o bien, de ser considerados solo víctimas de eventos externos, en este caso, del tráfico y comercio de la cocaína.

Ahora bien, como nos recuerda Mellino la agencia, "no ocurre nunca como un momento totalmente indeterminado, o libre, el actuar se da siempre al interno de un indeterminado horizonte de sentido" (2006:24 - la traducción es mía). Los Murui, tratarían entonces de obtener el control de la situación articulando su agencia a partir de sus propias estructuras conceptuales, en este caso, a partir de la perspectiva moral del uso inapropiado de la coca. Dicho uso apropiado de la coca, como estudiado por diversos investigadores (Echeverri 1997; Micarelli 2003; Pereira 2005; Echeverri \& Pereira, 2005; Román 2010; Cure 2014), tiene que ver como una concepción cultural de un uso y consumo de la coca regulado por una completa etiqueta, siendo principalmente un proceso de educación corporal y moral relacionado con la formación de saberes y de identidad masculina, que al mismo tiempo se vuelve una disciplina moral, una manera de aprender, de compartir, sabiendo dialogar. Es un saber encarnado a través de aquellas que Mauss (1971) denominó 'técnicas del cuerpo'.

Ese horizonte de sentido también aparece impreso en las historias de origen de la coca, en la que, en sus variadas versiones, aparece un momento en que un personaje desacata algunas normas y hace un uso indebido de la coca, lo que proporciona una serie de consecuencias desastrosas. La trasgresión actuada al no cumplir las reglas de uso apropiado de la coca, y sus complejas consecuencias son interpretadas como una experiencia ya vivida por las primeras generaciones desde tiempo originarios.

Como documentado por algunos antropólogos (Muratorio 1991; Echeverri 1997; Turner 1988; Hill 1988; Micarelli 2003) interesados en explorar las narrativas míticas y los modos de conciencia histórica entre las sociedades indígenas suramericanas y sus perspectivas 
sobre diversas situaciones de contacto con el mundo de los blancos, el mito, lejos de ser un sistema simbólico cerrado opuesto a las narrativas históricas, es, en cambio una estructura dinámica y negociada, un modo a través del cual se transmite y se difunde la conciencia histórica que, según Hill (1988), permite a los indígenas interpretar su sociedad y su pasado.

La conciencia mítica, tiende a asegurar "que las relaciones de contraste y diferencia socialmente más importantes no sean olvidadas o se vuelva meros objetos que puedan estar sometidas a manipulaciones instrumentales" (Turner 1988:6 - la traducción es mía). Los errores de las primeras generaciones están ahí, presentes, para resignificar situaciones contemporáneas. Se negocian de nuevo en el presente, en los diálogos sobre la coca, dotándose también de sentidos positivos, o bien, en la producción de experiencia social. "Como decían los abuelos", me advirtió Wenceslao, "tuvimos que vivir algunas cosas para poder dar consejos, si una persona no ha tenido esa experiencia, ¿cómo puede decirle a los otros de no hacerlo, como puede dar consejo a los otros? La bonaza de la cocaína nos enseñó que eso no era bueno, y fue a través de la misma coca que logramos salir de esa dramática situación...”

\section{A modo de conclusiones}

Un punto bien interesante que se evidenció en las conversaciones con los indígenas Murui es que a la coca no se le imputa una intencionalidad buena o mala. Es decir, ellos hablan de la coca de vida, coca verdadera, pero no se trata de que esa sea la esencia natural de la planta, algo que fuera dado. No es la planta en si misma a hacer considerada de vida, "todas las cosas buenas, tienen una parte negativa", explicaba Alfredo. La misma coca puede hacer mal, puede volverse "coca de guerra, de perdición, de seducción".

Esa perspectiva difiere de lo que sucede en los discursos oficiales de un país que como Colombia apoya la guerra contra las drogas, o como dice Taussig, "la guerra por las drogas" (2007:11 - la traducción es mía). La 'mata que mata', o enunciados relacionados como 
aquel de 'cultivos ilícitos' producidos por políticas públicas dirigidas a combatir el tráfico de las llamadas drogas, están legitimando y articulando discursos hegemónicos de orden nacional e internacional que criminalizan la plata de coca y los indígenas, campesinos, pequeños cocaleros que la cultivan ${ }^{6}$, mientras ciertamente no afectan a aquellos que ganan millones con el tráfico de cocaína, ni mucho menos meten en discusión el hecho de que quienes matan no son las plantas, sino la guerra impulsada. Discursos que abundan en el terreno del discurso común de la sociedad colombiana, que según Gramsci, "es aquel terreno de lo constituido y dado por descontado.... que se autorepresenta como la sabiduría tradicional o la verdad de los tiempos, pero en realidad es un producto profundamente histórico" (citado en Hall 2006:213-214).

El punto de vista indígena sobre la coca puede por el contrario colocarse en aquello que Viveiros de Castro (2002) ha definido 'perspectivismo amerindio' o bien, una teoría indígena amazónica según la cual el mundo está habitado por una multiplicidad de seres -animales, espíritus, muertos, habitantes de otros mundos, plantas, animalescada uno de los cuales se percibe como sujeto, dotado por una inteligencia autónoma, cuya identidad depende del punto de vista que asume en el mundo. La coca es entonces concebida como un sujeto, dotado de perspectiva propia, cuyo espíritu, seduce, engaña respeto a la relación que se establece entre 'ella sustancia' y quien la consume, una relación de interacción que se construye a través de una intención de quien mambea. Es finalmente el sujeto que hace un uso apropiado o menos de la sustancia.

\section{Notas:}

1 No todos los grupos amazónicos hacen uso del mambe y del ambil, en este caso estamos hablando principalmente de los Uitotos, o Murui - Muina, como ellos mismos se autodenominan. Para profundizar ver los trabajos de: Echeverri \& Pereira (2005) Mambear coca não é pintar a boca de verde: Notas sobre a origem e o uso 
ritual da coca amazónica; Micarelli (2003) Weaving a new basket: indigenous networks at the margin of development.

2 El trabajo de campo en el Amazonas fue desarrollado en diversas etapas, una preliminar en el 2009, por un mes, posteriormente 4 meses en el 2010, de septiembre a diciembre y luego otros 4 meses en el 2013, de marzo a junio.

3 La producción de cocaína comporta tres pasos. La hoja de coca es la única parte de la planta que contiene cocaína, de las hojas se pasa a la pasta base, también llamada basuco. Esta pasta se obtiene, primero mezclando la hoja triturada con agua y queroseno; después se separa el queroseno y de desecha la hoja de coca, se agrega agua más ácido sulfúrico, después de filtrado se mezcla con cal o amoniaco, el secado de esto da lugar a la pasta de coca. Su aspecto es de una pasta parda negra, fumable, pero bastante tóxica. De la pasta se pasa a la cocaína base, también denominada free-base, base libre, o crack, proviene de la mezcla de la pasta de coca con éter, al evaporarse con calor aparecen unos cristales casi puros de cocaína base muy potente, su aspecto es parecido a la porcelana, y triturado asemeja a escamas de jabón. Se fuma mezclado con el tabaco o se calienta en pipa de agua y se inhala el humo resultante. Finalmente, la cocaína o clorhidrato de cocaína, se obtenido a partir de la pasta base, con clorhídrico y extracción acetona etanol.

4 Ver nota 3 para entender lo que es el basuco.

5 Hace uno años, la agencia nacional contra estupefacientes sacó al aire una publicidad en radio y televisión en la que se refería a las plantas de coca, amapola y marihuana como 'matas que matan'. La publicidad fue demandada por la líder indígena Fabiola Piñacue y posteriormente fue eliminada.

6 Para profundizar ver Rivera (2003) Las fronteras de la coca. La Paz: Idis-Umsa, Ediciones Aruwiyiri.

\section{Referencias:}

BONILLA, Lydie. 2007. Des proies si desirables. Soumission et predation pour les Paumari D'Amazonie bresilienne. Tesis de Doctorado. Paris: Ecole des Hautes Études en Sciences Sociales.

BOURDIEU, Pierre. 1991. El sentido práctico. Sobre la teoría de la acción. Barcelona: Editorial Anagrama.

CASTELLS, Manuel. 2008. Volgere di millennio. Milano: Universitá Bocconi editori.

CLIFFORD, James. 1999. Itinerarios transculturales. España: Editorial Gedisa.

CURE, Salima. 2014. 'Ahora hay que mambear'. Prattiche e discorsi intorno al consumo urbano del mambe nelle cittá di Leticia e Bogotá. Tesis de Doctorado. Napoli: Universitá L'Orientale.

DREYFUS, Pablo. 1998. Cocaine, the military and shining path, 1890-1995. Documento presentado en el encuentro de la "Latin American Studies Association", Chicago. 
DURANTI, Alessandro. 2005. Antropologia del linguaggio. Roma: Meltemi editori.

ECHEVERRI, Juan A. 1997. The people of the center of the World. A study in Culture, History and Orality in the Colombian Amazon. Tesis de Doctorado. New York: New School for Social Research.

ECHEVERRI, J. \& PEREIRA, E. 2005. "Mambear coca não e pintar a boca de verde: Notas sobre a origem e o uso ritual da coca amazónica.” In LABATE, B. \& GOULART, S. (eds.): O uso ritual das plantas de poder, pp. 117-185. Campinas: Ed. Mercado de Letras, Fapesp.

GRELE, Ronald. 2007. "Introduzione”. In PORTELLI, A. (ed.): Storie Orali. Racconto, immaginazione, dialogo, pp. VII-XV. Roma: Donzelli editori.

HALL, Stuart. 2006. Il soggetto e la differenza. Per una archeologia degli studi culturali e postcoloniali. Roma: Meltemi editore.

HILL, Jonathan. 1988. "Introduction: myth and history”. In HILL, J. (ed.): Rethinking history and myth. Indigenous South american perspectives on the past, pp. 1-17. Urbana: Illinois Books edition

HUGH-JONES, Stephen. 1988. "Lujos de ayer, necesidades de mañana: comercio y trueque en la Amazonia noroccidental”. Boletín del Museo del Oro, 21:77103. (https://publicaciones.banrepcultural.org/index.php/bmo/article/ view/7154; acesso em 11/11/2010).

JEDLOWSKI, Paolo. 2002. Memoria, esperienza e modernitá. Memorie e societá nel XX secolo. Milano: Franco Angeli Editori.

MACHADO, Lia. 2000. "Limites e fronteiras: Da alta diplomacia aos circuitos da ilegalidade." Revista Territorio, 8:9-29.

MAUSS, Marcel. 1971. Sociología y antropología. Madrid: Tecnos editorial.

MELLINO, Miguel. 2006. "Introduzione". In HALL, S. (ed.): Il soggetto e la differenza. Per una archeologia degli studi culturali e postcoloniali, pp. 7- 29. Roma: Meltemi editore.

MICARELLI, Giovanna. 2003. Weaving a new basket:indigenous networks at the margin of development. Tesis de Doctorado. Urbana-Champaign: University of Illinois.

2012. Tobacco's Divine banknote: the translation of project money into public wealth. Trabalho apresentado no Congreso Internacional de Americanistas.Panel: "Images of Public Wealth: Property, Identity, and Wellbeing in Native Tropical America”. Vienna.

MURATORIO, Blanca. 1991. The life and times of grandfather Alonso. Culture and history in the upper Amazon. New Jersey: Rutgers University press.

. 1996. "Trabajo para la Shell: resistencia cultural a la proletarización en la amazonía ecuatoriana”. In SANTOS, F. (ed.): Globalización y cambio en la amazonia indígena, vol 1, pp. 371-395. Quito: Abya-yala.

NIETO, Valentina. 2006. Mujeres de la abundancia. Tesis de Maestría. Leticia: Universidad Nacional de Colombia.

NORDSTROM, Carolyn. 2007. "War on the front lines". In ROBBEN, A. \& SLUKA, J. (eds.): Ethnographic fieldwork. An anthropological reader, pp. 128-153. New Jersey: Blackwell publishing. 
OLIVEIRA, João P. 2013. "Curt Nimuendajú e a história Ticuna: elementos para uma reflexão crítica sobre a etnografia e o estatuto da etnologia”. Tellus, 13(24):227-259.

PEREIRA, Edmundo. 2005. Nimaira Uruki: esa es mi lucha. Ritual e politica entre os Uitoto-Murui, rio Carapana, Amazonia colombiana. Tesis de Doctorado. Rio de Janeiro: Museu Nacional-UFRJ. . 2012. Un Povo Sábio, Um Povo Aconselhado: Ritual e Política entre Os UitotoMurui. Brasília: Paralelo 15.

PIZZA, Giovanni. 2005. Antropologia medica. Saperi, pratiche e politiche del corpo. Roma: Carocci editore.

RIVERA, Silvia. 2003. Las fronteras de la coca. La Paz: Idis-Umsa, Ediciones Aruwiyiri.

ROMAN, Oscar. 2010. "Mito de la coca: el manejo y sus consecuencias." Mundo Amazónico, 1:315-326.

ROSALDO, Renato. 2000. Cultura y verdad. La reconstrucción del análisis social. Quito: Ediciones Abya-yala.

ROSEBERRY, William. 1988. "Political economy". Annual Review of Anthropology, 17:161-185.

SANTOS-GRANERO. Fernando. 1991. Amazonia 1940-1990. Lima: Terra NovaUniversidad Católica del Perú.

SLUKA, J. \& ROBBEN, A. 2007. "Fieldwork in anthropology: an introduction". In ROBBEN, A. \& SLUKA, J. (eds.): Ethnographic fieldwork. An anthropological reader, pp.1-28. New Jersey: Blackwell publishing.

SHERRAT, Andrew. 1998. "Introduzione: sostanze particolari”. In GOODMAN, J., LOVEJOY, P. \& SHERRAT, A. (eds.): Usi sacri, consumi profani. Il ruolo storico e culturale delle droghe, pp. 17-28. Genova: ECIG editori.

SOBERÓN, Ricardo. 2009. "Hacia una nueva Perspectiva en la Temática del Tráfico Ilícito de Estupefacientes”. In TOKATLIAN, J. (ed.): La Guerra contra las Drogas en el Mundo Andino. Hacia un Cambio de Paradigma, pp. 198-224. Buenos Aires: Libros del Zorzal.

TALLÉ, Cristiano. 2007. "Per una economía della pratica di ricerca sul campo overo sul sottile confine tra vita e ricerca". In GALLINI, C. \& SATTA, G. (ed.): Incontri etnografici, pp. 150-170. Roma: Meltemi

TAUSSIG, Michael, 2005. "Cultura del terrore, spazio della morte". In DEI, F. (ed.): Antropologia della violenza, pp. 77-123. Roma: Meltemi 2007. Cocaina. Per un'antropologia ella polvere bianca. Milano: Bruno Mondadori.

TOVAR-PINZÓN. Hermes. 1994. "La economía de la coca en América Latina. El paradigma colombiano". Revista Nueva Sociedad, 130:86-111.

TURNER, Terence. 1988. "History, myth and social consciousness among the Kayapo of Central Brazil". In HILL, J. (ed.): Rethinking history and myth. Indigenous South american perspectives on the past, pp.195-213. Urbana: Illinois Books edition.

URBINA, Fernando. 1992. Las hojas de poder. Bogotá: Universidad Nacional de Colombia editorial. 
URBINATI, Emilio. 2008. Politiche di sviluppo e questiones étnica. La cooperazione italiana in Bosnia. Tesis de Doctorado. Bologna: Universitá di Bologna.

VASCO, Luis Guillermo. 1999. "Vivir y escribir en antropología". Boletín de Antropología, 13 (30): 43-51. Medellín: Universidad de Antioquia.

VIVEIROS de Castro, Eduardo. 2002. "Los pronombres cosmológicos y el perspectivismo amerindio.” In ALLIEZ, E. (ed.): Gilles Deleuze una vida filosófica, pp. 763-777. Bogotá: Ministerio de asuntos extranjeros de Francia.

Resumo: Estou interessada no assunto da coca, o mambe (folhas de coca em pó), a cocaína, há alguns anos, quando completei meu mestrado em estudos amazônicos na Universidade Nacional da Colômbia, sede Amazônia. Morando e estudando em Letícia, escutava histórias que se referiam ao tempo do tráfico de cocaína dos anos 70-80 no Trapézio Amazônico, relacionado ao cultivo de coca na Bolívia e no Peru; também, ouvia outras que abordavam a natureza contemporânea desse negocio vinculado ao Brasil e a rota de Manaus ao Oceano Atlântico. Pouco a pouco, o interesse pelo assunto me levou a enfocar nas interpretações que os indígenas que consomem coca fazem sobre sua transformação em cocaína e nos efeitos que a comercialização dessa substância teve em suas vidas.

Palavras-chave: Coca, Cocaína, Murui, Amazônia, Respostas culturais.

Abstract: I have been interested in the subject of coca, mambe (powdered coca leaves) and cocaine for some years ago, since I completed my master's degree in Amazonian studies at the National University of Colombia (Amazonia campus). Living and studying in Leticia, I regularly encountered stories referring to the time of the cocaine trafficking in the 70s-80s around the Amazonian Trapezium, related to coca cultivation in Bolivia and Peru. In the same way, I was surrounded by stories that addressed the contemporary nature of this traffic and its link with Brazil and the route through Manaus to the Atlantic.Little by Little, my interest in the subject led me to focus on the interpretations that indigenous people who consume coca make about its transformation into cocaine, and on the effects that the commercialization of this substance has had on their lives.

Keywords: Coca, Cocaine, Murui, Amazônia, Respostas culturais. 